\title{
Self assessment of daytime sleepiness: patient versus partner
}

\author{
Ruth N Kingshott, Patricia J Sime, Heather M Engleman, Neil J Douglas
}

\begin{abstract}
Background - Patients with the sleep apnoea/hypopnoea syndrome (SAHS) and their spouses often differ in their assessment of the patient's sleepiness. A study was therefore undertaken to investigate whether either the patient's or partner's rating on the Epworth sleepiness scale (ESS) was better related to illness severity.

Methods - Nocturnal variables (apnoeas + hypopnoeas/hour (AHI) and arousals/ hour) and patient and partner ESS scores were compared in 103 new patients attending the sleep clinic.

Results - Mean patient and partner ESS scores were not different. In the whole population neither patient nor partner ESS variables correlated with AHI or arousal frequency. In the patients with SAHS (AHI $\geqslant 15$ ), partner ESS correlated weakly with AHI, but patient ESS did not. Conclusions - This study suggests that neither patient nor partner ESS ratings are strong predictors of SAHS severity. (Thorax 1995;50:994-995)
\end{abstract}

Keywords: sleep apnoea/hypopnoea syndrome, sleepiness, partner.

Excessive sleepiness is the most prevalent daytime symptom of the sleep apnoea/hypopnoea syndrome (SAHS), ${ }^{1}$ resulting in an increased risk of vehicle accidents. ${ }^{2}$ The multiple sleep latency test (MSLT) ${ }^{3}$ and its variant, the maintenance of wakefulness test (MWT), ${ }^{4}$ are used as objective methods for measuring daytime sleepiness, but are labour intensive and expensive to conduct. More simply, the Epworth sleepiness scale (ESS), ${ }^{5}$ a self administered questionnaire, provides a subjective estimation of daytime sleepiness. There is frequently a discrepancy between the patient and their partner's ESS assessment. The aim of this study was to determine if patient or partner's assessment of sleepiness is a better predictor of SAHS severity. ${ }^{6}$

\section{Methods \\ SUBJECTS}

One hundred and three patients referred for assessment of suspected SAHS were studied. Patients subsequently diagnosed with narcolepsy, periodic limb movement disorder, psychological or psychiatric illness were excluded from the study. The patients consisted of 87 men and 16 women of mean (SD) age 48 (13) years, with a mean apnoea/hypopnoea index (AHI) of $28(22)$ /hour slept, and a mean arousal index (see below) of 25 (18)/hour slept.

Overnight clinical polysomnography ${ }^{7}$ was recorded in the Scottish National Sleep Laboratory, with the nocturnal variables defined as follows: (1) An apnoea is the cessation of airflow for at least 10 seconds, ${ }^{8}$ and a hypopnoea is a $50 \%$ reduction in thoracoabdominal movement for at least 10 seconds. $^{8}$ (2) An arousal is an increase in electromyographic tone for at least 1.5 seconds associated with the return of alpha or theta rhythm. ${ }^{9}$

Patients' sleepiness was independently rated by both patients and partners using the ESS, which yields a total score corresponding to the chance of dozing in each of eight real life situations. ${ }^{5}$ In addition, the minimum ESS (minESS) and the maximum ESS (maxESS) values for each couple were analysed.

\section{DATA ANALYSIS}

Data were analysed using the SPSS-PC+ (SPSS Inc, Chicago, USA). Patient and partner ESS scores were compared using two tailed Wilcoxon tests, and relationships between nocturnal variables and ESS variables were evaluated by Spearman rank correlations.

\section{Results}

Patient and partner mean ESS scores (table 1) were not significantly different. In the whole population (table 2) no significant correlations were seen between nocturnal variables and ESS scores (figure). In the SAHS diagnosed subgroup (AHI $\geqslant 15$ ), patient ESS did not correlate significantly with nocturnal variables, whilst partner ESS and minESS scores correlated weakly but significantly with AHI (table 2). One quarter of patients with severe SAHS $(A H I \geqslant 50, n=16)$ scored below 10 on the ESS, in contrast to a previous study ${ }^{11}$ where all patients with severe SAHS $(n=19)$ scored 10 or more.

Table 1 Comparisons of mean (SD) patient and partner ESS scores in the whole population and in those with $A H I$ $\geqslant 15$

\begin{tabular}{llll}
\hline & $\begin{array}{l}\text { Patient mean } \\
\text { ESS score }\end{array}$ & $\begin{array}{l}\text { Partner mean } \\
\text { ESS score }\end{array}$ & p value \\
\hline $\begin{array}{l}\text { Whole sample } \\
(\mathrm{n}=103)\end{array}$ & $12(5)$ & $12(4)$ & NS \\
$\begin{array}{l}\text { AHI } \geqslant 15 \\
(\mathrm{n}=66)\end{array}$ & $12(5)$ & $11(4)$ & NS \\
\hline
\end{tabular}

ESS = Epworth sleepiness scale; AHI = apnoea + hypopnoea index (per hour slept); NS = non-significant $(p>0 \cdot 1)$. 
Table 2 Correlation matrix of nocturnal variables with ESS variables

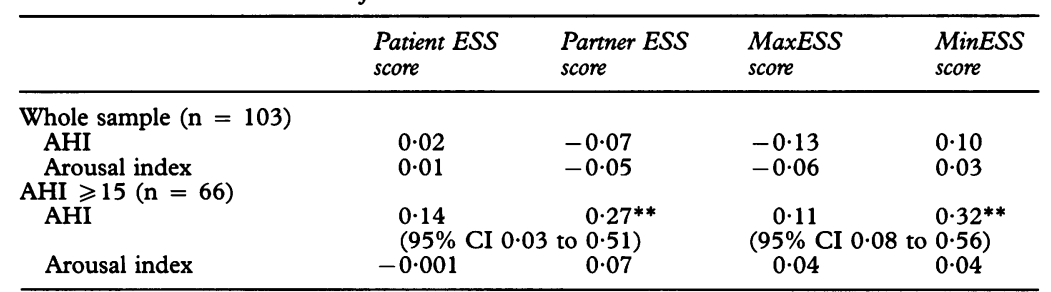

ESS = Epworth sleepiness scale; AHI = apnoea + hypopnoea index (per hour slept); $95 \%$ $\mathrm{CI}=95 \%$ confidence levels for significant $r$ values. ${ }^{* *} \mathrm{p}<0 \cdot 01$.

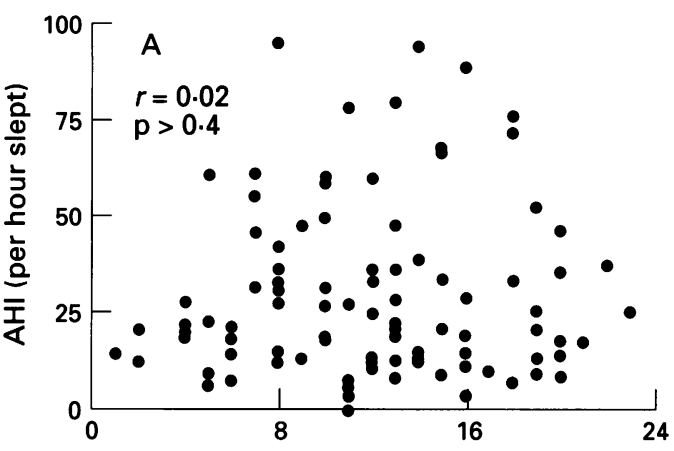

Patient Epworth sleepiness score

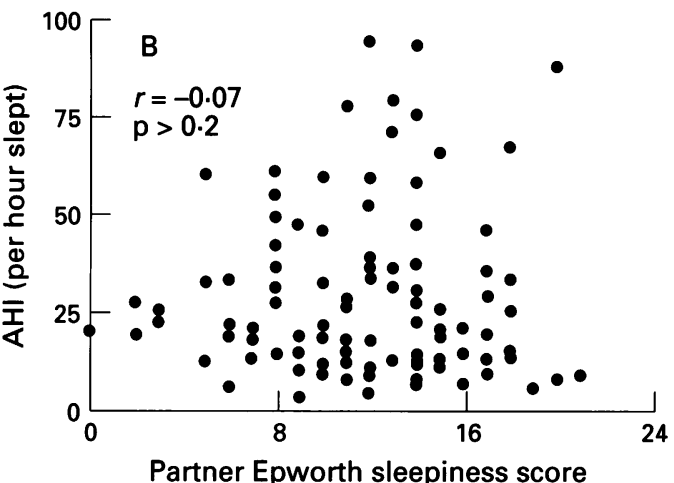

Rank correlation of apnoea + hypopnoea index (AHI) and Epworth sleepiness scale score in $(A)$ patient and $(B)$ partner.

\section{Discussion}

Analyses of the whole population indicate that patient and partner ESS scores are similar, in keeping with a smaller recent study. ${ }^{10}$ However, we have extended that study by showing that, in the whole group, there were no significant correlations between ESS variables and nocturnal variables for ratings of sleepiness by either the patient or partner.

In the subgroup of SAHS diagnosed patients $(A H I \geqslant 15)$ the patient's ESS rating was not significantly related to AHI. This contrasts with an earlier study ${ }^{11}$ where correlations $(r=0.44$, $\mathrm{p}<0.001)$ were found between patient ESS score and AHI in patients with SAHS by the originator of the ESS. We can see no obvious explanations for the discrepancy. The partner's ESS rating was significantly correlated with AHI, but only weakly. The minimum ESS score in a couple was better correlated with AHI than the larger of the two scores.

We believe that our failure to find significant correlations between ESS and SAHS severity has several causes which reflect the problems with subjective ratings. As part of human nature, some patients maximise and others minimise their symptoms. In addition, some patients with severe SAHS and severe objective sleepiness are so obtunded that they do not appreciate the severity of their symptoms, at least until after they are treated. ${ }^{12}$ Our failure to find any better correlation using partners' estimates of ESS may be due to a combination of two factors: (1) partners only observe patients over a limited part of the day, and thus have difficulty in making an accurate estimate on all points of the scale, and (2) the patients' complaints about sleepiness may influence the scoring by their spouses.

Alternatively, the lack of correlation between ESS and polysomnography results could mean that polysomnography is not providing useful measurements of disease severity. This seems unlikely as daytime sleepiness measured by the MSLT $^{3}$ correlates significantly with apnoea/ hypopnoea frequency and micro-arousal frequency but not with ESS score. ${ }^{13}$ Our data are supported by studies using other subjective sleepiness assessments - for example, Dement et $a l^{14}$ using the Stanford sleepiness scale found that subjective sleepiness correlated with sleep latency in normal subjects but not in patients with sleep apnoea. ${ }^{14}$

We conclude that the clinical predictive value of ESS scores is limited, with the results indicating that neither the patients' scores nor those of their partners are strong predictors of disease severity. Hence, the ESS alone cannot be used to determine the mode of investigation or the likelihood of an individual having SAHS.

1 Whyte KF, Allen MB, Jeffrey A, Gould GA, Douglas NJ. Clinical features of the sleep apnoea/hypopnoea syndrome. $Q$ F Med 1989;72:659-66.

2 George CF, Nickerson PK, Hanly PJ, Millar TW, Kryger MH. Sleep apnoea patients have more automobile accidents. Lancet 1987;ii:447.

3 Carskadon MA, Dement WC, Mitler MM, Roth T, Westbrooke PR, Keenan S. Guidelines for the multiple sleep latency test (MSLT): a standard measure of sleepsleep latency test (MSLT):
iness. Sleep 1986;9:519-24.

4 Mitler MM, Guijavarty KS, Browman CP. Maintenance of wakefulness test; a polysomnographic technique for evaluating treatment in patients with excessive somnolence. Electroencephalogr Clin Neurophysiol 1982;153 658-61.

5 Johns MW. A new method for measuring daytime sleepiness: the Epworth Sleepiness Scale. Sleep 1991;14:540-5.

6 Guilleminault C, van den Hoed J, Mitler MM. Clinical overview of the sleep apnoea syndromes. In: Guilleminault C, Dement WC, eds. Sleep apnoea syndromes. New York: Alan R Liss, 1978;1-12.

7 Douglas NJ, Thomas S, Jan MA. Clinical value of polysomnography. Lancet 1992;339:347-50.

8 Gould GA, Whyte KF, Rhind GB, Airlie MAA, Catterall $\mathrm{JR}$, Shapiro CM, et al. The sleep hypopnoea syndrome. Am Rev Respir Dis 1988;137:895-8.

9 Cheshire K, Engleman H, Deary I, Shapiro C, Douglas NJ. Factors impairing daytime performance in patients with sleep apnoea/hypopnoea syndrome. Arch Intern Med 1992; 152:538-41.

10 Johns MW. Sleepiness in different situations measured by the Epworth Sleepiness Scale. Sleep 1994;17:703-10.

11 Johns MW. Daytime sleepiness, snoring and obstructive sleep apnoea. Chest 1993;103:30-6.

12 George CF, Kryger MH. Sleep and sleepiness and the pulmonologist. Curr Pulmonol 1990;11:1-18.

13 Martin SE, Engleman HM, Deary IJ, Douglas NJ. Comparison of microarousal definitions in patients with sleep apnoea. Am F Respir Crit Care Med. 1995;151:A154.

14 Dement WC, Carskadon MA, Richardson G. Excessive daytime sleepiness in the sleep apnoea syndrome. In: Guilleminault C, Dement WC, eds. Sleep apnoea syndromes. New York: Alan R Liss, 1978:23-46. 